Supplement of Biogeosciences, 12, 3805-3818, 2015

http://www.biogeosciences.net/12/3805/2015/

doi:10.5194/bg-12-3805-2015-supplement

(C) Author(s) 2015. CC Attribution 3.0 License.

(c) (i)

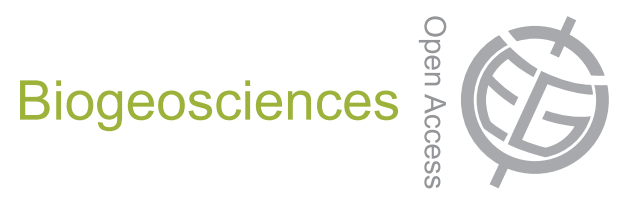

Supplement of

\title{
Carbon stocks and soil sequestration rates of tropical riverine wetlands
}

M. F. Adame et al.

Correspondence to: M. F. Adame (f.adame@griffith.edu.au)

The copyright of individual parts of the supplement might differ from the CC-BY 3.0 licence. 
1 Supplement

2

3 Table S1. Remote sensing products and standard terrain parameters for up-scaling

4 aboveground carbon (C) of mangroves of La Encrucijada Biosphere Reserve.

\begin{tabular}{|c|c|c|c|c|}
\hline $\begin{array}{l}\text { Aboveground } \mathrm{C} \\
\text { co-variable }\end{array}$ & Source & Date & $\begin{array}{l}\text { Spatial } \\
\text { resolution (m) }\end{array}$ & Provided by \\
\hline NDVI values & $\begin{array}{l}\text { SPOT } 5 \text { images } \\
(603 / 319,604 / 320)\end{array}$ & 2005 & 10 & $\begin{array}{l}\text { CONABIO, obtained from } \\
\text { Secretariat of the Navy in the } \\
\text { frame of "Mexican mangroves, } \\
\text { current state and long term } \\
\text { monitoring" }\end{array}$ \\
\hline $\mathrm{HH}$ backscattering & ALOS Palsar & 2010 & 25 & $\begin{array}{l}\text { EORC, JAXA } \\
\text { http://www.eorc.jaxa.jp/ALOS/en/p } \\
\text { alsar_fnf/fnf_index.htm }\end{array}$ \\
\hline HV backscattering & ALOS Palsar & 2010 & 25 & $\begin{array}{l}\text { http://www.eorc.jaxa.jp/ALOS/en/p } \\
\text { alsar_fnf/fnf_index.htm }\end{array}$ \\
\hline $\begin{array}{l}\text { SAGA GIS standard } \\
\text { terrain parameters* }\end{array}$ & $\begin{array}{l}\text { Digital Elevation } \\
\text { Model }\end{array}$ & 2013 & 15 & $\begin{array}{l}\text { INEGI, } \\
\text { http://www.inegi.org.mx/geo/conte } \\
\text { idos/datosrelieve/continental/Desc } \\
\text { arga.aspx }\end{array}$ \\
\hline
\end{tabular}

$5{ }^{*}$ Altitude above channel network, analytical hill shading, aspect, catchment area,

6 channel network base level, convergence index, Is factor, plan curvature, slope and

7 the topographic wetness index (Böhner, et al, 2006, Conrad, 2005) 

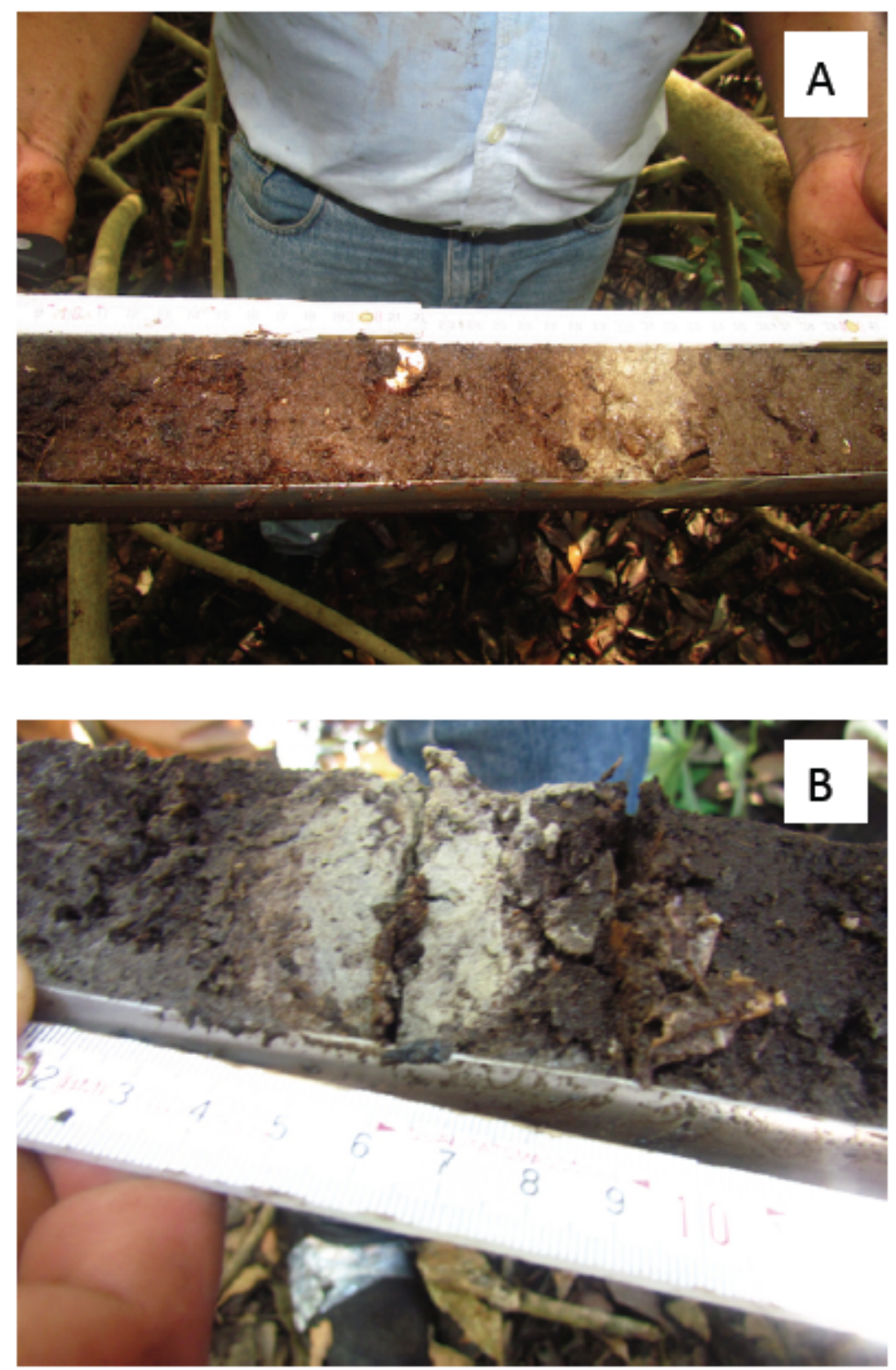

11 Figure S1. Plinian deposit forming an ash horizon in soil cores from La Encrucijada

12 Biosphere Reserve. The ash was deposited during the eruption of Santa Maria's

13 volcano in 1902. The natural marker was used to estimate carbon sequestration rates

14 as $\mathrm{C}$ accumulated in the soil profile. 

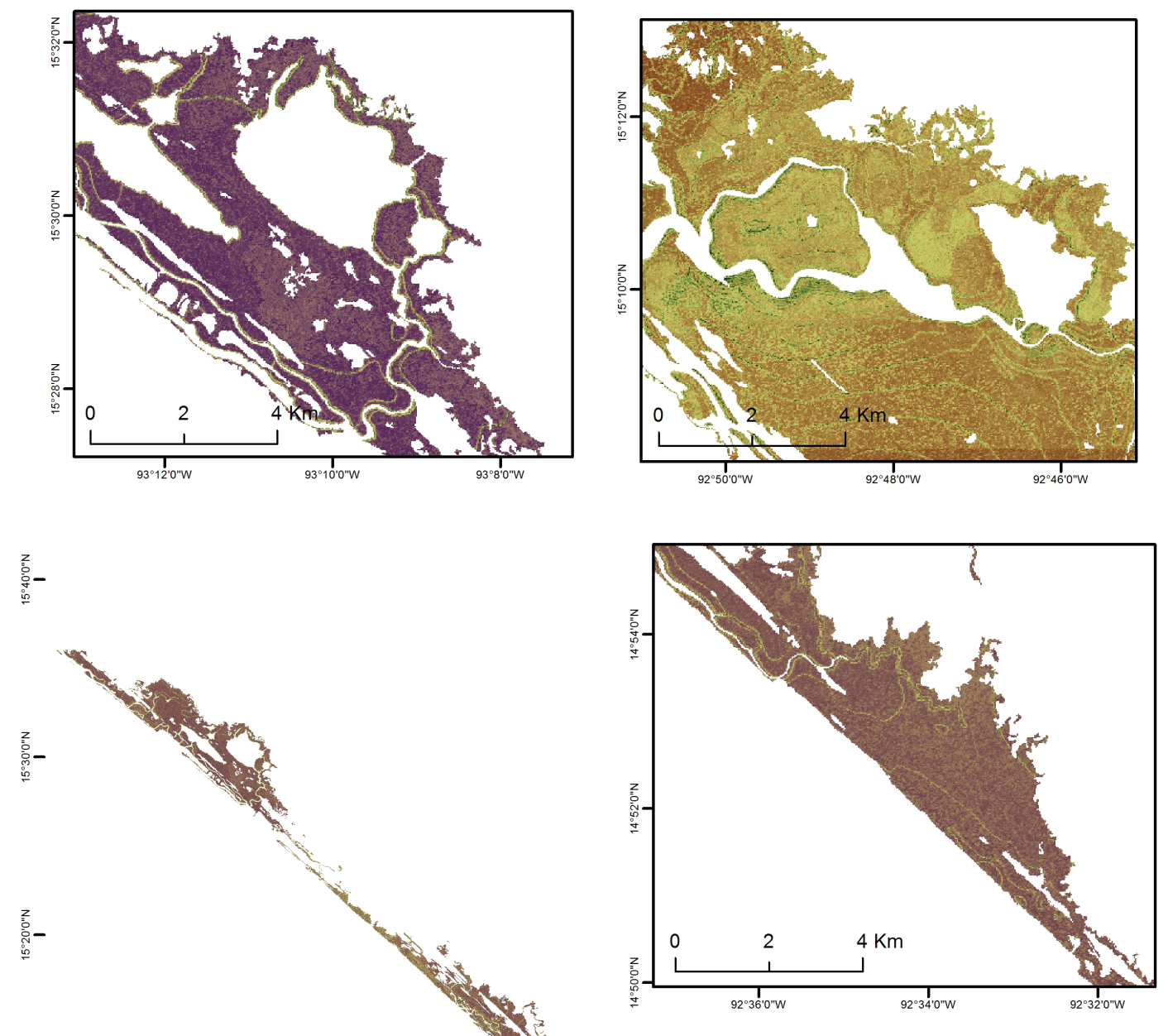

\section{㐔- RMSE: 161}
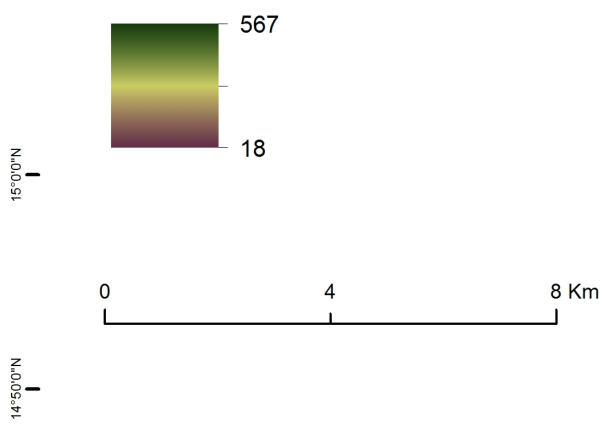

18 Figure S2. Aboveground C stocks (trees) $\left(\mathrm{Mg} \mathrm{ha}^{-1}\right)$ estimated for the La Encrucijada 

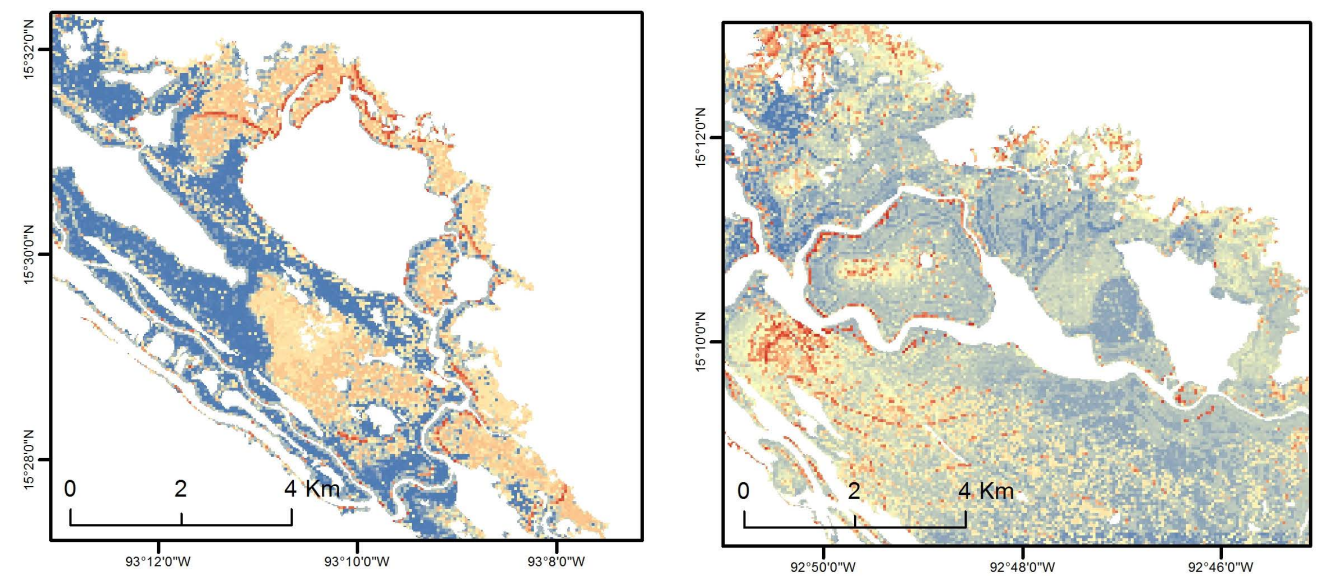

旁-
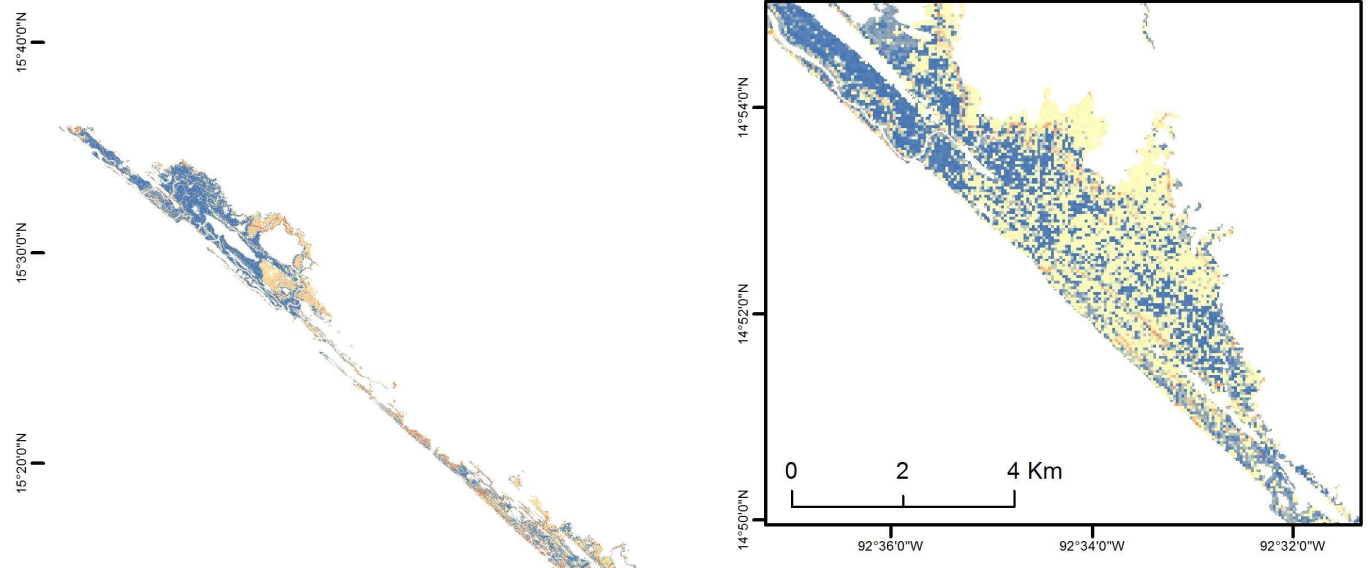

ํํำ

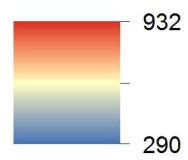

금-

290
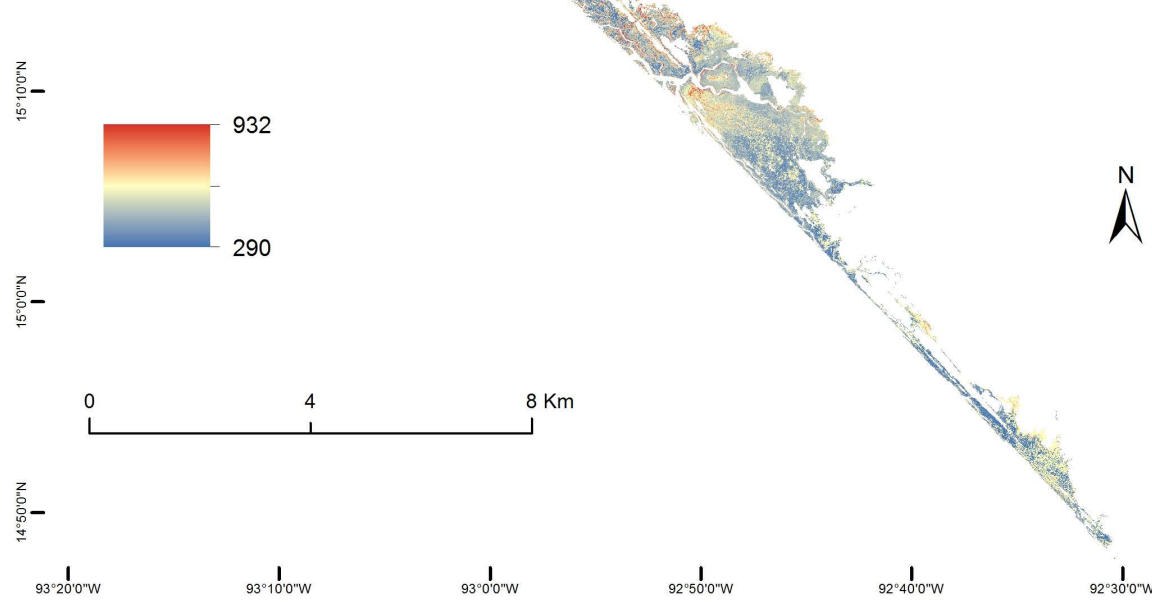

25 Figure S3. Uncertainty associated to aboveground $\mathrm{C}$ stock estimations $\left(\mathrm{Mg} \mathrm{ha}^{-1}\right)$ within La Encrucijada Biosphere Reserve 